\title{
Word recognition strategies amongst isiXhosa/English bilingual learners: The interaction of orthography and language of learning and teaching
}

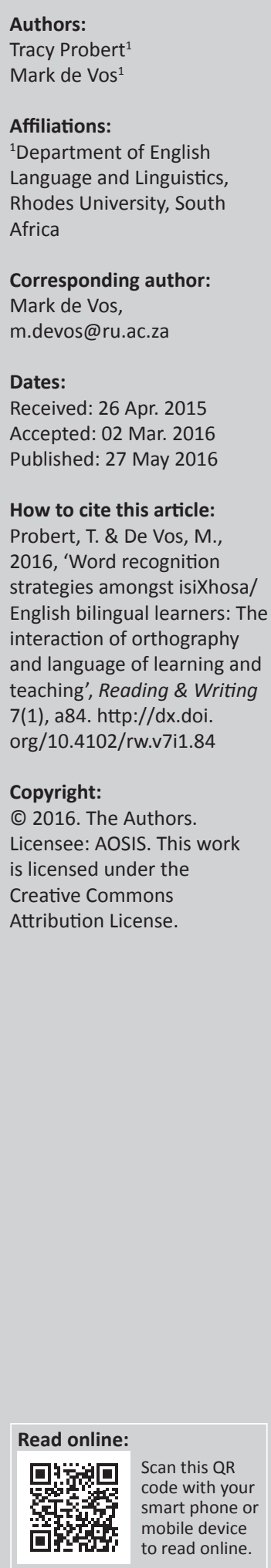

Word recognition is a major component of fluent reading and involves an interaction of language structure, orthography, and metalinguistic skills. This study examined reading strategies in isiXhosa and the transfer of these strategies to an additional language, English. IsiXhosa was chosen because of its agglutinative structure and conjunctive orthography. Data was collected at two schools which differed with regards to their language of learning and teaching (LoLT) in the first three years of schooling: isiXhosa and English respectively. Participants completed a wordand pseudo-word reading aloud task in each of two languages which hypothetically impose different cognitive demands. Skills transfer occurs to a limited extent when the language of first literacy uses a transparent orthography, but is less predictable when the language of first literacy uses an opaque orthography. We show that although there is transfer of word recognition strategies from transparent to deep orthographies, felicitous transfer is limited to sublexical strategies; infelicitous transfer also occurs when lexical strategies are transferred in problematic ways. The results support the contention that reading strategies and cognitive skills are fine tuned to particular languages. This study emphasises that literacies in different languages present readers with different structural puzzles which require language-particular suites of cognitive reading skills.

\section{Word recognition: A complex interplay of orthography, language structure, and cognitive skills}

Rapid and effortless word recognition is a major component of fluent reading (Aaron et al. 1999; Invernizzi \& Hayes 2010:196). Although reading straddles 'linguistic, neurolinguistic, cognitive, psychological, sociological, developmental and educational domains' (Pretorius \& Mokhwesana 2009:55), word recognition, has been studied as a set of related neurological processes. There are distinct neural pathways for recognition of gestalt-like whole words versus decomposing a complex word into its component parts. However, there are at least three issues that impact on these neural processes. Firstly, at a psycholinguistic level, words are defined through the structures of a language; different languages package different phonological and morphosyntactic features in different ways. Secondly, linguistic words are mediated in print through orthographies. Orthographies are, more often than not, a set of linguistic and sociocultural compromises developed in particular social contexts. For instance, although all South African Bantu languages are agglutinative in their linguistic structure, they may have either conjunctive or disjunctive orthographies, reflecting both the linguistic and social decisions that went into their transcription (Louwrens \& Poulos 2006). Thirdly, learners have at their disposal a number of cognitive tools which they use to solve the reading puzzles presented to them. These skills are dynamically developed through exposure to print orthography and include phonological and morphological awareness. These three sets of interacting factors conspire to make word recognition different in different languages and for different orthographies.

\section{Word structure in Bantu languages}

IsiXhosa, like all Bantu languages, has a relatively simple syllable structure based around a (C)V(V) template (Hua 2002). In addition, there are constraints on complex syllable onsets. Although some words appear to have a complex onset orthographically, these are often single consonants corresponding to single phonemes and not a true phonological cluster (1ab). In contrast, English allows for more complex structures than CV, such as CCV and CCCV words (2ab):

(1) a. CV: Dla.la [lzala]

$$
\text { 'Play' }
$$

Note: We use the internationally accepted term, 'Bantu' to refer to the Bantu group within the Niger-Congo language family. We do not use the term to refer to people as occurred during the apartheid regime. We acknowledge that the use of the term Bantu has derogatory connotations in lay usage within the Republic of South Africa but use it in its technical sense in this article. The authors take full responsibility for this usage. 
b. CV: Hla.ba [laba]

'Stab'

(2) a. CCV: try [trai], glue [glu:]

b. CCCV: straw [stro:], strew [stru:]

The nature of words is language specific (Guthrie 1948; Louwrens \& Poulos 2006; Prinsloo 2009). All Bantu languages are agglutinating and consequently a Bantu word includes rich, overt morphology. For example, nouns include noun class prefixes as well as stems whereas verbs include morphological reflexes of subject marking, object marking, tense, aspect, mood, causativity, and negation among others. The result is that Bantu words (particularly nouns and verbs) tend to be much longer than their English equivalents.

Linguistic structure is mediated through orthography. Because linguistic words may differ from orthographic words, learners are faced with language-specific processing challenges when attempting to recognise words in a particular language. These challenges, in turn, presuppose languagespecific reading strategies. For example, Nguni languages are written conjunctively and the Tswana and Sotho language groups tend to be written disjunctively. In (3a), a conjunctive writing system yields only one orthographic word also corresponding to one morphological word. The orthographic word ngiyabathanda (3a) is therefore both a morphological word and an orthographic word. In contrast, in disjunctive orthographies, a linguistic word may correspond to a number of orthographic words (3b):

(3) a. Ngi-ya-ba-thand-a

SM1.1sG-PRES-OM2-like-Fv

'I like them' (isiZulu)

b. ke a ba rat-a

SM1.1sg pres OM2 like-fv

'I like them' (Northern Sotho - Taljard \& Bosch 2006:433).

This correspondence between orthographic and morphological words is a characteristic feature of conjunctive orthographies which distinguishes them from disjunctive scripts, such as Northern Sotho (3b) and English (Taljard \& Bosch 2006), although all South African Bantu languages have aspects of both conjunctive and disjunctive systems triggered by linguistic context (Louwrens \& Poulos 2006).

The reason for the utilisation of different orthographies is based on both historical and phonological considerations. Historically, orthographies were developed by European missionaries. Although prescriptive and colonial suppositions may have influenced their decisions (Van Wyk 1987), the two languages necessitate different orthographies based on their phonological systems (Louwrens \& Poulos 2006). In the Nguni languages the presence of phonological processes, such as vowel elision and vowel coalescence make the use of a disjunctive orthography impractical. Example (4a) demonstrates how the two vowels ' $a$ ' and ' $u$ ' coalesce into ' $o$ ', which makes a disjunctive rendering at odds with the phonetic pronunciation; (4b) demonstrates vowel coalescence between ' $a$ ' and ' $i$ ' yielding ' $e$ ':
(4) a. Utata na umama $\rightarrow$ realised as: utata nomama father and mother b. inciniba na inja $\rightarrow$ realised as: inciniba nenja ostrich and dog

Louwrens and Poulos (2006) demonstrate convincingly that Tswana is mostly written disjunctively except in contexts where phonological processes obscure the underlying forms; in these contexts, Tswana is written conjunctively. Thus, orthographic choices mediate linguistic structural considerations. There remain significant questions about how orthographies and language structures conspire to make the reading experience different for different learners. Nevertheless, in South Africa, the relationship between language structure and orthography are not always reflected in pedagogy: teacher training is oriented to English and Afrikaans; indigenous language curriculum documents are often translated directly from English and therefore reflect English teaching concerns (Bikitsha \& Katz 2013).

There are limited studies on agglutinating languages which could shed light on how reading occurs in isiXhosa. However, some research on Turkish has been done. The structure of Turkish, like that of isiXhosa is agglutinating and the orthography is conjunctive in character. Durgunoğlu and Öney (1999) found that, in Turkish, a phonologically transparent orthography fosters early development of word recognition skills, and that phonological awareness contributes to word recognition in the early stages of reading acquisition. These results were attributed to the phonological and orthographic characteristics of the Turkish language and orthography.

\section{IsiXhosa and orthographic depth}

Written languages may differ with respect to orthographic depth and consistency. Orthographic depth refers to the degree to which there are one-to-one correspondences between graphemes and linguistic categories (such as phonemes or syllables) (Aro 2004). The source of opacity within the English orthography partly derives from historical spellings, dialectal speech differences, borrowing, and the fact that there are more phonemes in the spoken language than there are graphemes to represent them (Frost 2005). Consequently, there is a relative lack of one-to-one correspondences between phonemes and graphemes. The second factor, consistency, involves the uniqueness of pronunciation of an orthographic segment. Therefore if two words are spelled similarly but pronounced differently (such as MOTH-BOTH), the letter cluster OTH is considered inconsistent (Frost 2005; Widjaja \& Winskel 2004). English has a very high number of words with irregular and unpredictable spellings, included in foundation phase vocabulary (e.g. one, two, four, five, eight, and nine). The irregularity and inconsistency of English orthography results in a deep orthography where readers rely less on grapheme-to-phoneme representation and more so on whole-word processing. In contrast, isiXhosa has a fairly transparent, consistent, alphabetic orthography which is more amenable to sublexical processing. 
Orthographic depth affects acquisition and development in reading (Pillunat \& Adone 2009; Sprenger-Charolles 2003) and influences the cognitive process of word recognition (Yamashita 2013). According to the Orthographic Depth Hypothesis $(\mathrm{ODH})$, reading in a shallow orthography predisposes readers to rely more on decoding and phonological processing because of the direct and reliable grapheme-phoneme mapping. For deep orthographies, it is hypothesised that readers tend to rely more on orthographic processing because of the opacity in the relationship between grapheme-to-phoneme mapping. Therefore differences in orthographic depth determine the dominant type of information (lexical or sublexical) used in word recognition in the brain (Katz \& Frost 1992; Yamashita 2013).

Within a cognitive approach to word recognition, one way of understanding the interaction of orthography and reading is through a dual route model (DRC) of word recognition (Levy et al. 2009; Perre \& Ziegler 2008; Simon \& Van Herreweghe 2010). The model was originally developed to show differential word recognition in adult learners but can also potentially assist in understanding word recognition among L2 learners.

The model suggests the existence of two distinct processing routes for word recognition - a lexical (direct route) and a sublexical (indirect) route. With respect to the lexical route, the brain recognises a word in its entirety (perhaps as a type of picture or gestalt); the word is accessed directly from the lexicon. Consequently, for the processing of written language, the lexical route processes frequent and orthographically irregular words, such as yacht or one, but fails to process unfamiliar or pseudo-words, such as braston, which have no meaning at all, because, by definition, such words would be novel occurrences (Invernizzi \& Hayes 2010; Levy et al. 2009).

In contrast to this, the sublexical route subdivides words into smaller segments and maps those to linguistic constituents, together making up the word in a bottom-up fashion (Eskey \& Grabe 1988; Lisson \& Wixson 1991). The bottom-up model of reading is concerned with the recognition of individual letters, phonemes, and words and the reading process begins with individual recognition of letter and phonemic counterparts (Eskey \& Grabe 1988). According to the bottomup model, learners learn to read through their ability to sound out letters through grapheme-to phoneme correspondences. Only once the learner has these decoding skills can he/she move onto the meaning of the words in the text (Lisson \& Wixson 1991). For top-down processing, the reader starts with a general idea or schema of what should be in the text and uses this in perceiving and interpreting the orthographic text (Eskey \& Grabe 1988).

Most typically, it is assumed that graphemes are mapped to phonemes, although Grain Size Theory (Ziegler \& Goswami 2005) also suggests the possibility of sublexical processing involving syllables or morphemes. The sublexical route can process pseudo and real words which have a grapheme-tophoneme representation but would fail to process irregular words which violate this representation (Levy et al. 2009). This is an important distinction which is exploited in our methodology by using pseudo-words to factor out topdown, lexical recognition processes.

Pseudo-words are 'pronounceable combinations of letters which lack semantic meaning but which can be decoded and pronounced via phonological processing and alphabetic (letter-sound) knowledge' (Fredrickson, Frith \& Reason 1977 cited in Thomson, Crewther \& Crewther 2006:290). Zock, brane, and repaki are all examples of English pseudo-words; lebina, warona, and menida are examples of isiXhosa pseudo-words. Pseudo-word reading tasks are commonly used as a measure of phonological processing and word recognition across diverse fields of reading research (Thomson, Crewther \& Crewther 2006). According to Siegel (2004) 'It is a well established fact that reading of pseudo-words is one of the best measures of phonological processing in an alphabetic language' (cited in Pillunat \& Adone 2009:3). Because readers have never encountered a particular pseudo-word before, they cannot rely on top-down recognition processes such as contextual clues or previous sight word familiarity. Rather it requires a reader to recall the phoneme associated with each grapheme and blend the separate sounds together in order to form a pronounceable unit. Pseudo-word reading therefore provides an accurate assessment of the learner's ability to apply grapheme-to-phoneme knowledge in decoding (Rathvon 2004). However, pseudo-words are not merely an experimental task; they are also an indication of how learners may approach new words with which they are unfamiliar. In the context of school and higher education, ongoing learning involves routinely being exposed to new, unfamiliar words and it is therefore important that learners can cope with them. This makes the pseudo-word paradigm a particularly powerful and illuminating technique.

Transparent orthographies are often associated with faster initial learning trajectories. Wimmer and Goswami (1994) studied reading development in young English and German learners and found that the English learners had substantially more difficulties in decoding tasks than German learners did. These findings were attributed to the transparency of the German orthography. According to Wimmer and Goswami (1994), when learners learn to read using transparent orthographies they make use of the sublexical route, which ultimately ensures successful decoding. However, when approaching reading in a deep orthography, such as English, the learners recognise words via the lexical route. Similarly, Seymour, Aro and Erskine (2003) found that acquisition of a transparent orthography requires access to only one of two decoding strategies, as seen in the sublexical route, whereas acquisition of deep orthographies requires the implementation of both decoding strategies. Likewise, Defior, Martos and Cary (2002), comparing Spanish and Portuguese learners, showed that the accuracy in the pseudo-word reading of Spanish and Portuguese learners 
was relatively similar to the performance of German learners and much better than that reported for English learners in the aforementioned studies.

\section{The different puzzles presented by different orthography or structure pairings}

The tension between linguistic language structure and orthography results in different written languages presenting very different reading challenges to learners. Important cognitive skills such as phonological and morphological awareness are used in different ways for different language/ orthography combinations and emerge in acquisitionally different ways (Bialystok 2002; Geva \& Siegel 2000; Goswami 1999; Ota 2010 inter alia). There is thus a very tight relationship between language, orthography, and the particular cognitive strategies used in reading:

Literacy emerges out of the specific knowledge of the linguistic forms and orthographic principles of individual language and is unique to each of the learner's languages. Factors such as orthographic depth, for example, determine what strategies learners will need to use when learning to read the language and the success they will achieve as they acquire these skills. (Bialystok 2002:164-165)

In equivalent texts, English will present readers with larger numbers of shorter words in an idiosyncratic and unpredictable orthography; isiXhosa presents readers with smaller numbers of longer, morphologically complex words in a highly regular syllabic pattern and a relatively transparent orthography. Clearly, then, because the nature of words differs between languages, the cognitive problem of word recognition must be particularised too. Therefore, there is no one-size-fits-all approach to fluent reading across languages. Automaticity occurs through at least two neurological pathways and these are conditioned by orthography and language structure. This raises the important question of how these skills are transferred to reading in an L2. Despite this, Bantu languages are notably absent from the literature on word recognition and cross-orthography comparisons. It is this gap that our research attempts to come to grips with; with these issues in mind, our study focuses on, (1) what groups of strategies are used in word recognition and (2) how differences in transparency between two completely different orthographies and language families affect word recognition in bilingual learners.

\section{Methodology}

Participants undertook isolated word- and pseudo-word reading tasks in both isiXhosa and English. An analysis of incorrect responses allowed a comparison of type of reading strategies (lexical and sublexical) used by learners was made across two schools which differed with regards to their language of learning and teaching (LoLT).

\section{Participants}

Data were collected from a sample of 47 Grade 4 isiXhosa home language learners from two different schools. The learners were tested individually at their school by the researcher and an assistant. The first school (which we will refer to as School X) is an isiXhosa-medium school in a coastal town in the Eastern Cape $(n=31)$. The school is a well-run and well-resourced public school on the outskirts of a township. Learners receive three years of isiXhosa LoLT followed by English as LoLT in their fourth year. Therefore they had been learning in English for approximately 6 months at the time of testing. The second school (School E) is an English-medium school in an inland town in the Eastern Cape $(n=16)$. School E is a former model $\mathrm{C}$ public school and has learners from diverse backgrounds. The selected learners from School E are home language isiXhosa speakers who have been taught in English from the start of their school career. IsiXhosa is taken as an additional language in this school. The learners from this sample, although isiXhosa home language speakers, have only been exposed to written isiXhosa for six months.

It is important to bear in mind that although the learners from both School $X$ and School $E$ have isiXhosa as their L1 and English as their L2, their exposure to the two orthographies is very different. The learners from School $X$ are educated in isiXhosa for three years up until the end of Grade 3, where they make the 'switch' to English as the LoLT. However once this 'switch' has been made, these learners still speak isiXhosa in their homes and on the playground. The learners from School E however are educated in English, often from preschool age. They are only taught isiXhosa formally as an additional language from Grade 4 and English remains their LoLT. Most of these learners will speak isiXhosa at home, but at school they tend to interact with their friends in English. Thus the two Schools will often be discussed in contrast to one another.

Table 1 provides a breakdown of the two schools involved in this study. The language of first literacy (the language the child first learns to read in), alternatively referred to as the child's language of learning and teaching, and the learners' first and second languages are outlined for each school.

\section{Procedure}

The learners completed a set of reading tasks, including both word- and pseudo-word reading, in both English and isiXhosa. Each reading task consisted of a list of 10 words, with three practice words used to familiarise the learners with the task. The number of tokens obtained from each learner is thus 49 in each language. All pseudo-words were pronounceable, adhered to the orthographic conventions of the language being tested, and had been checked with L1 speakers of isiXhosa beforehand. Instructions were given orally by the assistant in both English and isiXhosa to ensure

TABLE 1: Languages used at School $X$ and School E.

\begin{tabular}{lcc}
\hline Variable & School X $(\boldsymbol{n}=\mathbf{3 1})$ & School E $(\boldsymbol{n}=\mathbf{1 6})$ \\
\hline Language of first literacy (LoLT) & IsiXhosa & English \\
L1 & IsiXhosa & IsiXhosa \\
L2 & English & English \\
\hline
\end{tabular}


that learners understood what was required of them. To ensure that all children were given the same instructions, the same assistant was used at both schools, with all the children. The assistant received formal training leading up to data collection and was given explicit guidelines on how to phrase the instructions for the learners. Learners were presented with the words and pseudo-words one by one in the form of flashcards and they were then instructed to read the words out loud. Learners' responses were recorded for more indepth analysis. Words were randomised in order to secure the most accurate results. Half of the learners were tested in isiXhosa first and the other half were tested in English first so as to avoid any priming effects. The stimulus materials also controlled for word length (number of syllables) and syllable structure (simple vs. complex consonant clusters).

Table 2 provides examples of the stimuli presented to the learners for both isiXhosa and English real- and pseudoword reading.

\section{Data coding and analysis}

The real word reading task investigated the different word recognition strategies which isiXhosa/English bilingual learners adopted when approaching the reading of real words in English and isiXhosa. According to the ODH, (Katz \& Frost 1992), different orthographies promote different kinds of word recognition processes. Transparent orthographies like isiXhosa promote sublexical decoding, whereas opaque or deep orthographies like English promote whole-word recognition. One might therefore expect these processes to be evident from the errors made by learners. When there is adherence to alphabetic decoding (grapheme to phoneme mapping) in word recognition, the common errors which occur are those of mispronunciations (i.e. phoneme substitutions, deletions, insertions etc.), whereas the common errors which occur with orthographic (whole word) reading word recognition strategies are lexically primed, real-word substitution errors (i.e. Related but Wrong) (Wimmer \& Goswami 1994).

When learners identify and read the real-word stimulus correctly, this shows that they are able to recall and transfer pronunciation already taught to them before the items were encountered. The learner also draws on their knowledge of the orthography to interpret the words correctly. However, it does not necessarily shed any light as to whether the words are being recognised through lexical or sublexical processes. However, when learners make a mistake, the nature of the error may provide an indication of the underlying processes. In contrast, because pseudo-words have not been previously

TABLE 2: Examples of stimuli.

\begin{tabular}{|c|c|c|c|c|}
\hline Language & $\begin{array}{l}\text { CV SHORT } \\
\leq 2 \text { syllables }\end{array}$ & $\begin{array}{l}\text { CV Pseudo- } \\
\text { words SHORT } \\
\leq 2 \text { syllables }\end{array}$ & $\begin{array}{l}\text { CV LONG } \\
\geq 3 \text { syllables }\end{array}$ & $\begin{array}{l}\text { CV pseudo- } \\
\text { words LONG } \\
\geq 3 \text { syllables }\end{array}$ \\
\hline English & $\begin{array}{l}\text { 1. do } \\
\text { 2. he } \\
\text { 3. buy }\end{array}$ & $\begin{array}{l}\text { 1. } \mathrm{tu} \\
\text { 2. ra } \\
\text { 3. bi }\end{array}$ & $\begin{array}{l}\text { 1. calamari } \\
\text { 2. telephone } \\
\text { 3. garage }\end{array}$ & $\begin{array}{l}\text { 1. molibe } \\
\text { 2. lebina } \\
\text { 3. repaki }\end{array}$ \\
\hline Xhosa & $\begin{array}{l}\text { 1. vuka } \\
\text { 2. molo } \\
\text { 3. xola }\end{array}$ & $\begin{array}{l}\text { 1. mavu } \\
\text { 2. quxe } \\
\text { 3. lubo }\end{array}$ & $\begin{array}{l}\text { 1. sikelela } \\
\text { 2. qabela } \\
\text { 3. sukuma }\end{array}$ & $\begin{array}{l}\text { 1. zekuda } \\
\text { 2. sukibo } \\
\text { 3. fumeti }\end{array}$ \\
\hline
\end{tabular}

TABLE 3: Nominal scale used for coding data.

\begin{tabular}{|c|c|c|}
\hline Nominal Code & Description of response & Example \\
\hline \multicolumn{3}{|c|}{ General error types } \\
\hline 0 & Inaudible or unclear responses & \\
\hline 1 & $\begin{array}{l}\text { Unrelated phonologically or } \\
\text { semantically. }\end{array}$ & Elephant for Telephone \\
\hline \multicolumn{3}{|c|}{ Lexically primed, whole-word recognition error types } \\
\hline 2 & $\begin{array}{l}\text { Similar to stimulus but } \\
\text { phonologically or semantically } \\
\text { ill formed. }\end{array}$ & $\begin{array}{l}\text { Arch for ache } \\
\text { [a:t]] for [eık] } \\
\text { Take for think } \\
\text { [teik] for [OInk] }\end{array}$ \\
\hline \multicolumn{3}{|c|}{ Sublexical, decoding error types } \\
\hline 3 & $\begin{array}{l}\text { Largely correct - Addition of a } \\
\text { phoneme (sound) }\end{array}$ & Dumpoba for Dupoba \\
\hline 4 & $\begin{array}{l}\text { Largely correct - Deletion/ } \\
\text { omission of a phoneme (sound) }\end{array}$ & $\begin{array}{l}\text { Motiva for Motivate } \\
\text { [meutivə] for [meutivəlt] }\end{array}$ \\
\hline 5 & $\begin{array}{l}\text { Interaction effects (Pronounced } \\
\text { as English/isiXhosa) }\end{array}$ & $\begin{array}{l}\text { Use of clicks in English words } \\
\text { e.g. [lalamafi] for [kalama.ii] }\end{array}$ \\
\hline
\end{tabular}

encountered and can only be parsed using sublexical processes, correct reading of pseudo-words demonstrates an ability to decode words sublexically by matching the correct grapheme to a phoneme. Conversely, inability to complete the task shows inability to undertake this mapping.

The learners' responses in the reading tasks were coded on a 6-point nominal scale (Table 3 ). The analysis of the results was interpreted using comparative descriptive statistics and Fisher's exact chi-squared test, which is useful for categorical data in the analysis of determining the significant association (contingency) between two kinds of groups and is used when nominal data are less than five (Fisher 1954).

Table 3 presents the 6-point nominal scale on which the learners' responses were recorded. This scale is divided into three separate sections - general error types; lexically primed, whole-word recognition error types; and sublexical, decoding error types. An example from the data set is presented alongside each error type.

\section{Findings}

\section{Findings: Word recognition in a language of learning and teaching}

\section{School E}

IsiXhosa-speaking learners in School E, with English as an LoLT, made nine mistakes when reading English real words, the language with which they were most familiar. A breakdown of the error types (Figure 1) shows that $45 \%$ were lexically primed errors ('related but wrong'), $44 \%$ involved the deletion of a segment, and $11 \%$ were segment substitutions. Learners made more errors $(n=22)$ during the pseudo-word reading task. In contrast to the reading of real English words, the reading of English pseudo-words in School E showed only $4 \%$ for lexically primed guesses with sublexical decoding shown to be more actively used as the errors involved those of substitution (41\%), epenthesis and ellipsis (18\%). This shows that learners largely decode pseudo-words with sublexical strategies as expected.

These data demonstrate, that known English words are recognised using a combination of whole-word recognition $(55 \%)$ and sublexical strategies (45\%) (contrary to Pillunat 


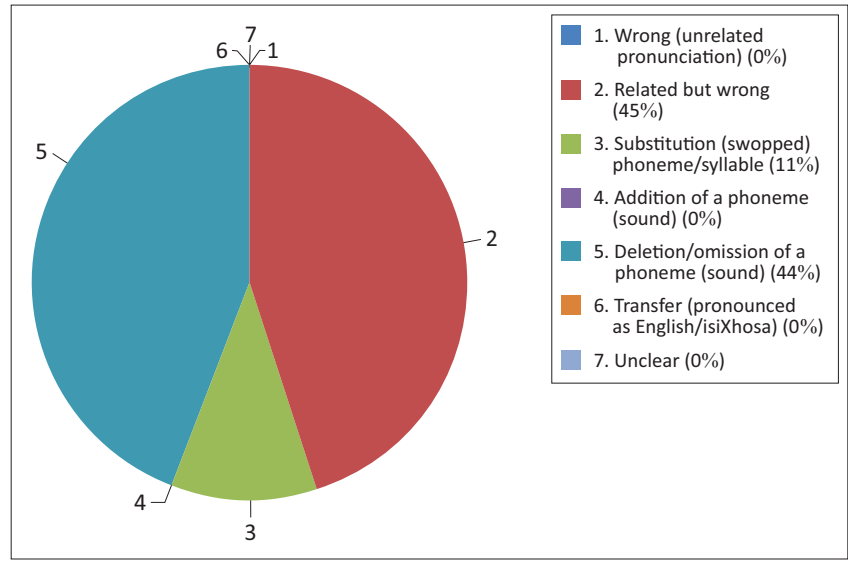

FIGURE 1: School E English real word reading $(n=9)$. A mixture of lexical and sublexical strategies.

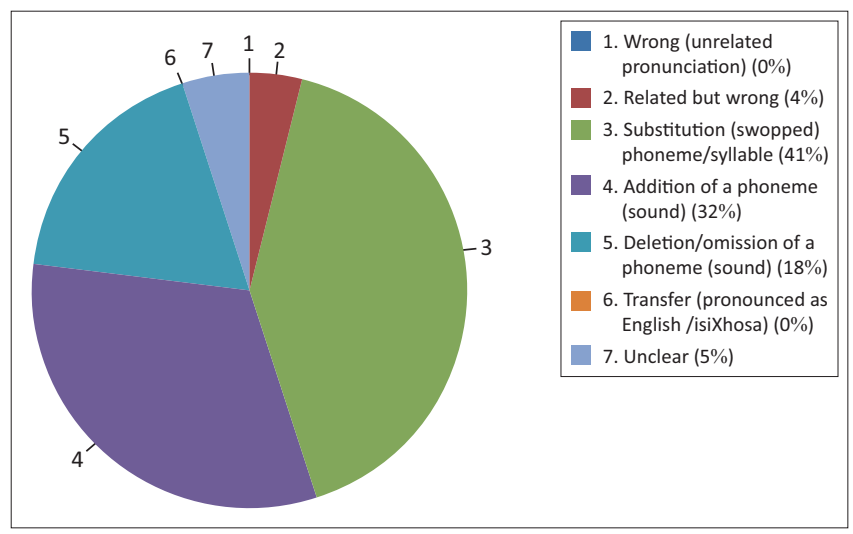

FIGURE 2: School E English pseudo-word reading $(n=22)$. Mostly sublexical strategies.

and Adone 2009). In contrast, pseudo-words are decoded using sublexical strategies. This is as expected given that these words are unknown to the learners and therefore, by definition, cannot be processed using whole-word recognition.

The different distributions of the different reading strategies for English real- and pseudo-word reading in School E are showed in Figures 1 and 2. Figure 1 shows that for real-word reading, $45 \%$ of error types were lexically primed ('related but wrong') errors, with 55\% being sublexically primed errors. In contrast, the results for the pseudo-word reading task showed only $4 \%$ of errors to be lexically primed, with $96 \%$ being sublexically primed errors.

\section{School X}

At School X, where the LoLT is isiXhosa, 26 errors were made when reading isiXhosa real words. As in Figure 3, which presents the distribution of the different error types among these learners, the majority (84\%) are decoding errors, including 58\% substitution errors, $19 \%$ insertion errors, and $7 \%$ deletion errors. Similarly for pseudo-words, as in Figure 4 , $90 \%(n=87)$ are decoding errors, including 55\% substitution, $30 \%$ insertion, and $5 \%$ deletion. These data show that learners at School $X$ overwhelmingly use sublexical decoding strategies for isiXhosa. These data are consistent with the

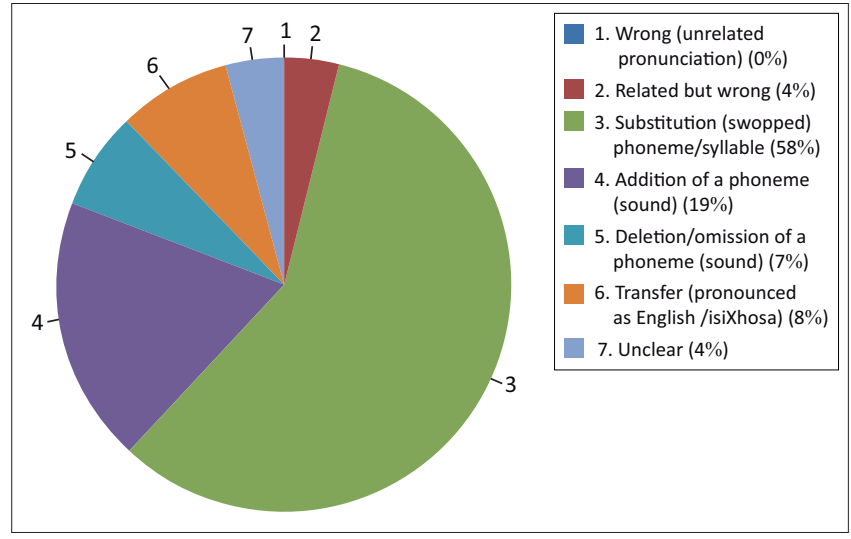

FIGURE 3: School $\mathrm{X}$ isiXhosa real-word reading $(n=26)$. Sublexical decoding strategies.

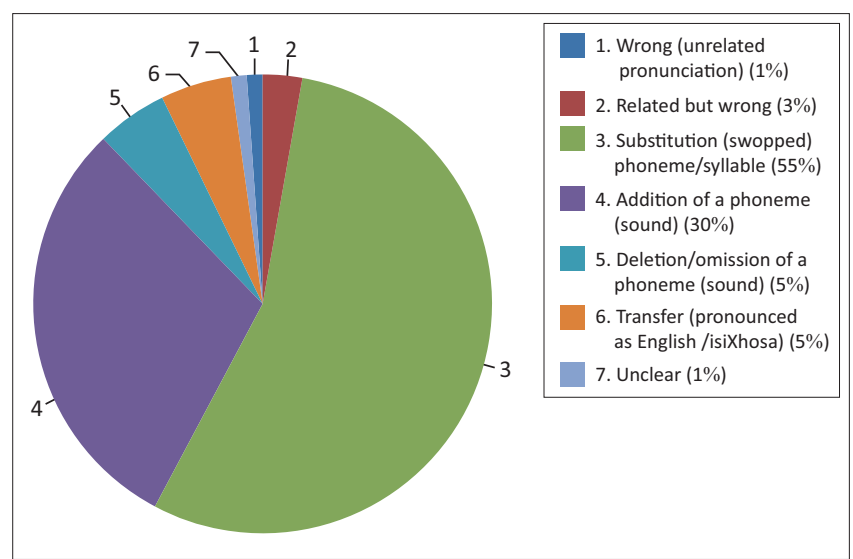

FIGURE 4: School X isiXhosa pseudo-word reading $(n=87)$. Sublexical decoding strategies.

$\mathrm{ODH}$ which correlates orthographic transparency with sublexical decoding and opacity with whole-word recognition (Katz \& Frost 1992; Yamashita 2013).

\section{Findings: transfer effects: Word recognition in a non-language of learning and teaching}

Having ascertained the strategies used in reading in the language in which literacy was first acquired (i.e. the LoLT), we now turn to the question of whether these reading skills can be transferred to reading another language introduced at a later stage (the language of second literacy). To do this, we investigated the strategies used by School $X$ learners in reading English and School E learners in reading isiXhosa. ${ }^{1}$

\section{School X}

IsiXhosa-speaking learners at School $\mathrm{X}$, when reading English words made 64 errors with a variety of strategies being used: lexical primed errors (33\%) and decoding errors (41\%: segment substitution $17 \%$, segment deletion $24 \%$ ). These data are also consistent with the reading of English pseudo-words where lexical priming accounts for $28 \%$, and decoding $59 \%$ (ellipsis $45 \%$ and substitution 14\%). This shows that a

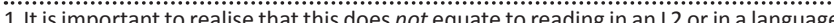
with which the learners are unfamiliar. At School E, all learners tested were Li speakers of isiXhosa - but had merely acquired literacy in English first. They were thus very familiar with isiXhosa. Similarly, although all learners at School X were L1 isiXhosa, they were all able to converse in basic English. 
combination of lexical and sublexical strategies is used to read both real- and pseudo-words in English.

Evidence for the use of whole or sight word recognition was seen when the learners replaced an unfamiliar word which was presented to them with a related word which they knew. They were thus using the shape of the word in their word recognition strategy, referred to as the theory of bouma shape in word recognition studies (Larsen 2004). A common example of this is where the learner was presented with the word, 'sphere,' and they said 'shape', or 'wheel' and they responded 'well'. These learners are therefore making use of phonetic or visual cues for word recognition which entails guessing the word from the word base (Aaron et al. 1999).

In some instances, there was direct transfer of orthographic conventions. Evidence for this transfer can be seen where clicks were substituted when learners read certain English real words (for example, square [s! hare], macaroni [malaroni], and calamari [lalamari]). The English grapheme is perceived as an isiXhosa phoneme and is therefore read using isiXhosa conventions. When this occurs, the learners are making use of phonological processing when attempting to decode the English words. Similarly, some putative instances of segment deletion are actually reanalysis of an orthographic segment in a way consistent with the structure of the language. Thus, it was found that in certain instances the learners were actually transferring orthographic conventions across orthographies and not deleting. This is seen in words such as, ' $\mathrm{p}^{\mathrm{h}}$ one' for phone and ' $\mathrm{t}$ hink' for think, where the learner is placing an isiXhosa value on an English grapheme. They read the ' $\mathrm{ph}$ ' as an aspirated ' $\mathrm{p}^{\mathrm{h}}$ '. These errors were recoded as instances of transfer when the errors sounded typical of an L2 speaker. School $X$ is thus making use of phonological decoding.

Figure 5 and Figure 6 present the distribution of error types according to reading strategy. For English real-word reading (Figure 5) it is shown that $33 \%$ of errors were lexically primed, with $58 \%$ being sublexical errors and $9 \%$ being completely incorrect. A similar distribution is seen for the English pseudo-word reading (Figure 6) with $23 \%$ of errors being lexical and $71 \%$ sublexical.

\section{School E}

When reading real isiXhosa words, learners at School E used sublexical decoding (100\%: substitution $73 \%$ and segment insertion 27\%). This is consistent with the way they approached English pseudo-words (Figure 4). Interestingly however, the same learners approached isiXhosa pseudowords in a completely different way. Instead of using decoding strategies, $70 \%$ of errors were lexically primed guesses (for example, 'arch' for 'ache', 'science' for 'silence'), with only $15 \%$ being decoded. This shows that the learners from School E were attempting to guess words based on whole-word recognition and general cognitive skills - but doing so incorrectly.

The use of both grapheme to phoneme correspondences (sublexical) as well as whole-word recognition (lexical)

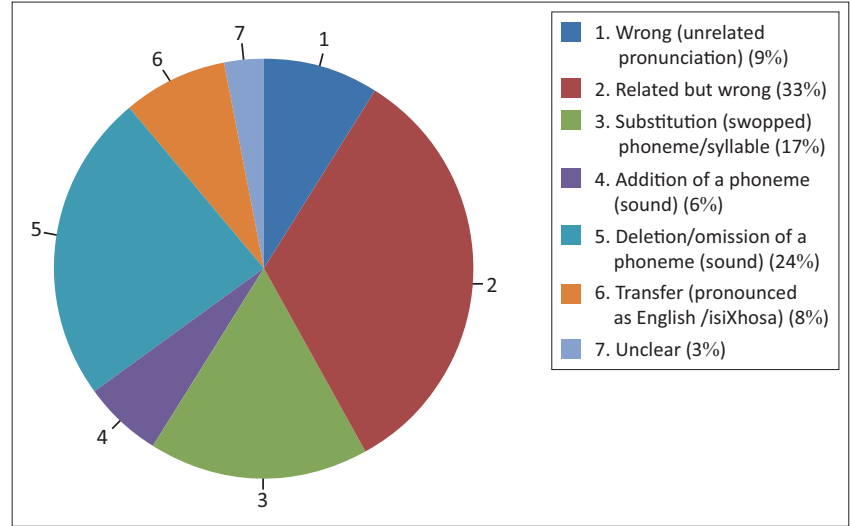

FIGURE 5: School X English real words $(n=64)$. Combination of Lexical and sublexical strategies.

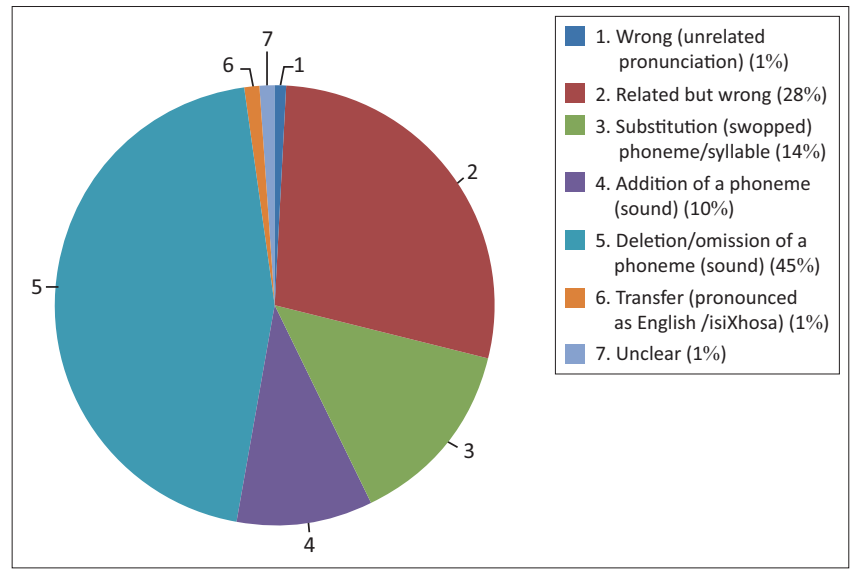

FIGURE 6: School X English Pseudo-words $(n=114)$. Mixed strategies (lexical and sublexical).

strategies in word recognition could be explained as individual differences in the learners' reading styles. The learners who are decoding grapheme to phoneme are making use of what is called bottom-up processing whereas those learners who are reading the words through direct recognition are making use of top-down processing in their interpretation of the words. According to Holm and Dodd (1997) skilled reading can only happen successfully if there is interaction between top-down processing and bottom-up processing in the recognition of unfamiliar words.

When the learners approach a pseudo-word in the language in which they are familiar they are able to distinguish between the word being a real word or a nonsense word and thus resort to alphabetic decoding (grapheme to phoneme correspondences) in their word recognition strategy in order to break down the word to make meaningful sense of it. However in the instance of learners from School E it was found that when faced with the interpretation of a word which they are unfamiliar with they are unable to separate the real words from the pseudo-words and thus rely on a 'guessing' strategy (otherwise known as phonetic cue or visual cue reading) resulting in sight word reading of the words. According to Holm and Dodd (1997) when the phonological awareness has not developed in the language in which the learner is attempting to read in, learners are limited to whole-word visual word recognition strategies. 


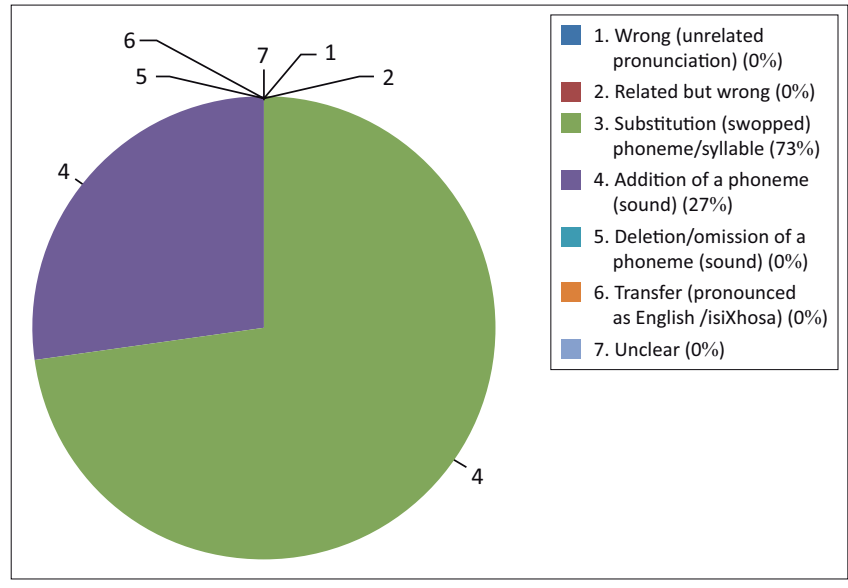

FIGURE 7: School E isiXhosa real-word reading $(n=15)$. Sublexical decoding strategies.

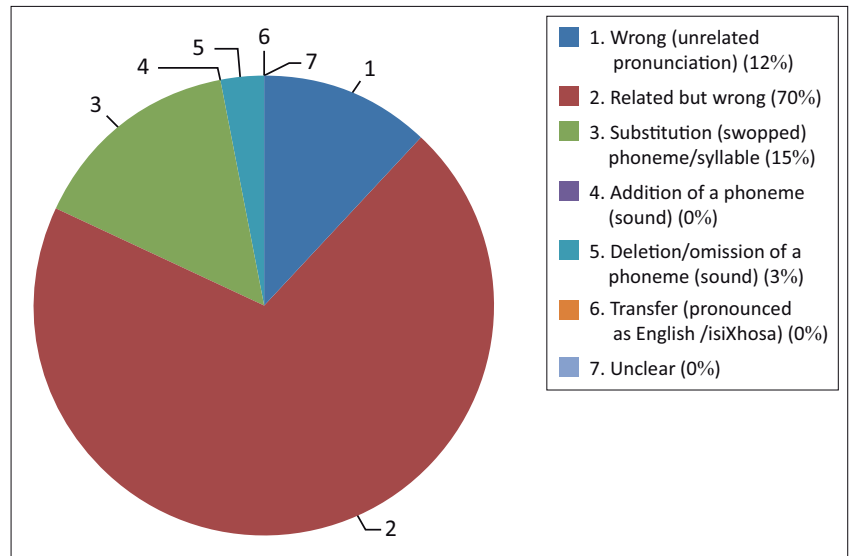

FIGURE 8: School E isiXhosa pseudo-word reading $(n=40)$. Mostly lexical strategies.

The pie-graphs below present a summary of the error types made by the learners from School E for isiXhosa real- and pseudo-word reading. Figure 7 shows that all errors were a result of sublexical decoding, with $73 \%$ being substitution errors and $27 \%$ addition errors. In contrast, the distribution of errors in Figure 8 shows $70 \%$ of errors were lexicallyprimed errors and $18 \%$ sublexical.

\section{Discussion}

The findings of the previous section are schematically represented as generalisations in the following graphic (Table 4). Our data suggest more nuance is needed in the theoretical models, namely the ODH and Dual-Route Cascaded Model of Word Recognition. The current models are deterministic and predict binary outcomes within word recognition (Seidenberg 1992). This study, however, showed that learners can use a number of different reading strategies within and across orthographies. According to Coady (1979) learners who are acquiring a second language use the strategies which they find most useful in their first language. Therefore the significant issue is not whether the skills used in the first language transfer to the second language, but rather how these skills are applied (Holm \& Dodd 1997).
Table 4 presents a summary of the different word recognition strategies used by learners from School X and School E for both real- and pseudo-word reading in their language of first literacy and language of second literacy (the language of literacy in which a learns to read, introduced in Grade 4).

Firstly, the data show that reading in LoLT is not identical but is determined by the parameters of the language being read. Thus, isiXhosa LoLT learners use decoding strategies for both real- and pseudo-words. This is consistent with the $\mathrm{ODH}$ which claims that transparent orthographies promote the use of decoding strategies. In contrast, English LoLT learners use a combination of lexical and sublexical strategies for realword reading but use mainly sublexical strategies to decode pseudo-words. This also appears to be consistent with the $\mathrm{ODH}$, given that written English is relatively opaque. ${ }^{2}$ This supports our contention that there is no one-size-fits-all approach to reading and that different languages pose different cognitive puzzles for readers.

Secondly, although our findings support the claim that there is transfer of word recognition skills from transparent orthographies to deep orthographies (Pillunat \& Adone 2009; Siegel 2004), even when the languages are of different structures and language families, felicitous transfer seems largely limited to sublexical, decoding skills. In contrast, with respect to whole-word recognition, it appears that literacy skills can be transferred to a non-LoLT in problematic ways - non-transfers and infelicitous transfers. Both of these are problematic because both can lead to reading difficulties. Non-felicitous transfers are evident when isiXhosa LoLT learners transfer decoding skills to English real words, and do not use as much whole-word recognition as English LoLT learners do for English real words. This is expected given that the transparency of isiXhosa orthography may not promote whole-word recognition and/or that isiXhosa LoLT learners have not yet achieved automaticity of recognition. However, this is not to say that isiXhosa LoLT learners do not use any whole-word recognition; they tend to favour a sublexical approach, most likely because, unlike an opaque orthography, a transparent one does not a priori preclude the use of a lexical recognition strategy. However, if, isiXhosa LoLT learners have not necessarily mastered whole-word recognition as a skill, it cannot be successfully transferred to English realword contexts. This can be contrasted with English LoLT learners who acquire both whole-word recognition as well as decoding strategies and are able to transfer decoding strategies to isiXhosa real words.

Infelicitous transfers tended to occur, for example, when English LoLT learners infelicitously transfer whole-word recognition to isiXhosa pseudo-words. One is led to ask why they do not decode isiXhosa pseudo-words $100 \%$ of the time. When learners who are literate in an opaque orthography realise that a word is potentially 'real' they decode it. But

2.This data also suggests that LoLT is more significant than L1. Both groups are learners are matched for L1 (isiXhosa) but their reading strategies owe more to the properties of the LoLT. This is good news for classrooms where learners come from multilingual backgrounds as it suggests that contradictory influences of L1 may be able to be reduced. 
TABLE 4: Summary of the different word recognition strategies employed.

\begin{tabular}{|c|c|c|c|c|c|}
\hline \multirow[t]{2}{*}{ Language } & \multicolumn{2}{|c|}{ School X } & \multirow[t]{2}{*}{ Language } & \multicolumn{2}{|c|}{ School E } \\
\hline & Words & Pseudo-words & & Words & Pseudo-words \\
\hline LoLT (isiXhosa) & Sublexical:96\% & Sublexical:97\% & LoLT (Eng) & Mixed:sublexical 50\% & Sublexical:90\% \\
\hline - & $\downarrow_{\text {Transfer of sublexical skills }}$ & $\prod_{\text {Transfer of sublexical skills }}$ & - & $\downarrow_{\text {Transfer of sublexical skills }}$ & $\begin{array}{l}\downarrow_{\text {Infelicitous transfer of whole-word }} \\
\text { recognition }\end{array}$ \\
\hline
\end{tabular}

when confronted with a pseudo-word and are able to identify it as such, they use whole-word recognition. In contrast, isiXhosa LoLT learners are able to draw on decoding strategies in approaching pseudo-words. This suggests that an isiXhosa LoLT in the foundation phase might better prepare learners for transferring (a subset of) skills to reading English.

\section{Conclusion}

It appears that learners literate in a transparent orthography are indeed able to transfer decoding skills more easily than learners literate in an opaque orthography. The data also confirms that learners literate in an opaque orthography can transfer skills to another language, but that transfer can have problematic effects; transfer of lexical strategies can set them up for failure and they do not always transfer sublexical decoding strategies to novel contexts.

The implications of this are important. If different languages imply different combinations of reading strategies then it is presumably important that these be reflected in pedagogy. Thus, reading in languages like isiXhosa needs to be taught differently to reading in English. To our knowledge, there is no formal training provided to teachers in this regard, especially in context where isiXhosa CAPS documents are translations of English ones.

This also means that care must be taken when introducing reading in an L2. Traditionally, this occurs in Grade 4 when learners who have been taught in isiXhosa are suddenly thrust into a context where English takes over as LoLT, and where it is assumed as matter of course that literacy skills transfer. Our data suggest that isiXhosa decoding skills can transfer under these circumstances but that isiXhosaspeaking learners do not necessarily have mastery of the whole-word recognition skills necessary for becoming fluent English readers.

Although non-transfers can be remedied, more serious are infelicitous transfers which imply that a skill has to be unlearned. Our findings also suggest that introducing additional languages of literacy during the foundation phase (i.e. before the skills for literacy in any single language have been consolidated) may be problematic. It is well known that learners struggle with the change in LoLT in Grade 4 and in an attempt to deal with this, since 2015, up to three languages are being taught in Foundation phase classrooms. The noble intention behind this suggests that earlier exposure to English literacy will help learners cope with the switch in Grade 4.
Our data suggest that such interventions should be managed with care. The literacy skills necessary in isiXhosa-reading classrooms are not the same suite of literacy skills necessary in English reading classes. Care must therefore be taken to, (1) use language-specific teaching methods, (2) reduce the possibility of learner confusion, (3) to be understanding of the types of non-transfer and infelicitous transfer that may take place and (4) to provide learners with adequate practice in all languages of literacy so that they are able to consolidate their reading skills. There is a real danger that in many current teaching contexts, none of these steps will be taken. At the very least, educators must remain open to the need for further research.

\section{Acknowledgements Competing interests}

The authors declare that they have no financial or personal relationships which may have inappropriately influenced them in writing this article.

\section{Authors' contributions}

T.P. and M.d.V. contributed equally to the writing of this article.

\section{References}

Aaron, P.G., Joshi, R.M., Ayotollah, M., Ellsberry, A., Henderson, J. \& Lindsey, K., 1999, 'Decoding and sight-word naming: Are they independent components of word recognition skill?', Reading and Writing: An Interdisciplinary Journal 11, 89-127. http://dx.doi.org/10.1023/A:1008088618970

Aro, M., 2004, Learning to read: The effect of orthography, Department of Psychology, University of Jyvaskyla.

Bialystok, E., 2002, 'Acquisition of literacy in bilingual learners: A framework for research', Language Learning 52(1), 159-199. http://dx.doi.org/10.1111/1467 9922.00180

Bikitsha, N. \& Katz, J., 2013, 'An analysis of the isiXhosa Home Language CAPS for the Foundation Phase, and the implications thereof for the teaching, learning and assessment of phonics and meaningful reading in isiXhosa', presented at RASA 2013 Johannesburg, October 25-27, 2013.

Coady, J., 1979, 'A psycholinguistic model of the ESL reader', in R. Mackay, B. Barkman \& R.R. Jordan (eds.), Reading in a second language, Newbury House, Rowley.

Defior, S., Martos, F. \& Cary, L., 2002, 'Differences in reading acquisition development in two shallow orthographies: Portuguese and Spanish', Applied Psycholinguistics 23, 135-148. http://dx.doi.org/10.1017/S0142716402000073

Durgunoğlu, A.Y. \& Öney, B., 1999, 'A cross-linguistic comparison of phonological awareness and word recognition', Reading and Writing: An Interdisciplinary Journal 11, 281-99. http://dx.doi.org/10.1023/A:1008093232622

Eskey, D.E. \& Grabe, W., 1988, 'Interactive models for second language reading: Perspectives on instruction', in P.L. Carrell, J. Devine \& D.E. Eskey (eds.), Interactive approaches to second language reading, CUP, Cambridge.

Fisher, R.A., 1954, Statistical methods for research workers, Oliver and Boyd.

Frost, R., 2005, 'Orthographic systems and skilled word recognition processes in reading', in 'M.J. Snowling \& C. Hulme (eds.), The science of reading: A handbook, pp. 272-295, Blackwell, Oxford.

Geva, E. \& Siegel, L.S., 2000, 'Orthographic and cognitive factors in the concurrent development of basic reading skills in two languages', Reading and Writing: An Interdisciplinary Journal 12, 1-30. http://dx.doi.org/10.1023/A:1008017710115 
Goswami, U., 1999, 'Casual connections in beginning reading: The importance of rhyme', Journal of Research in Reading 22(3), 217-240. http://dx.doi.org/10.1111/14679817.00087

Guthrie, M., 1948, The classification of the Bantu languages, Oxford University Press for the International African Institute, London.

Hua, Z., 2002, Phonological development in specific contexts, Cromwell Press Ltd, Britain.

Holm, A. \& Dodd, B., 1997, 'The effect of first written language on the acquisition of English literacy', Cognition 59, 199-147.

Invernizzi, M. \& Hayes, L., 2010, 'Developmental patterns of reading proficiency and reading difficulties', in R. Allington \& A. McGill-Franzen (eds.), Handbook of reading disabilities research, International Reading Association, Newark.

Katz, L. \& Frost, R., 1992, 'The reading process is different for different orthographies: The orthographic depth hypothesis', in R. Frost \& L. Katz (eds.), Orthography, phonology, morphology, and meaning, North Holland, Amsterdam.

Larsen, K., 2004, The science of word recognition, Advanced Reading Technology, Microsoft Corporation, viewed from http://www.microsoft.com/typography/ ctfonts/wordrecognition.aspx

Levy, J., Pernet, C., Treserras, S., Boulanouar, K., Aubry, F., Démonet, J.F. et al., 2009, 'Testing for the dual-route cascade reading model in the brain: An fMRI effective connectivity account of an efficient reading style', PLoS One 4(8), 1-13. http:// dx.doi.org/10.1371/journal.pone.0006675

Lisson, M.Y. \& Wixson, K.K., 1991, Assessment and instruction of reading disability: An interactive approach, Harper Collins Publications, New York.

Louwrens, L.J. \& Poulos, G., 2006, 'The status of the word in selected conventional writing systems - The case of disjunctive writing', Southern African Linguistics and Applied Language Studies 24(3), 389-401. http://dx.doi.org/10.2989/16073610609486427

Ota, M., 2010, Is a FAN always FUN? Phonological and orthographic effects in bilingual visual word recognition, School of Philosophy and Language Sciences, University of Edinburgh.

Perre, L. \& Ziegler, J.C., 2008, 'On-line activation of orthography in spoken word recognition', Brain Research 1188, 132-138. http://dx.doi.org/10.1016/j. brainres.2007.10.084

Pillunat, A. \& Adone, D., 2009, Word recognition in German primary school learners with English as a second language: Evidence for positive transfer? University of Cologne, Germany, viewed 16 March 2013, from http://www.bu.edu/bucld/ files/2011/05/33-Pillunat.pdf

Pretorius, E. \& Mokhwesana, M., 2009, 'Putting reading in Northern Sotho on track in the early years: Changing resources, expectations and practices in a high poverty school', South African Journal of African Languages 1, 54-73.
Prinsloo, D., 2009, 'Current lexicography practice in bantu with specific reference to the Oxford Northern Sotho School Dictionary', International Journal of Lexicography 22, 151-178. http://dx.doi.org/10.1093/ij1/ecp009

Rathvon, N., 2004, Early reading assessment: A practitioner's handbook, The Guilford Press, New York.

Seidenberg, M.S., 1992, 'Beyond orthographic depth in reading: Equitable division of labor', in R. Frost \& L. Katz (eds.), Orthography, phonology, morphology and meaning, pp. 85-118, North-Holland, Oxford, England.

Seymour, P.H.K., Aro, M. \& Erskine, J.M., 2003, 'Foundation literacy acquisition in European orthographies', British Journal of Psychology 94, 143-174. http://dx.doi. org/10.1348/000712603321661859

Siegel, L.S., 2004, 'Bilingualism and reading', in T. Nunes \& P. Bryant (eds.), Handbook of learner's literacy, pp. 673-690, Kluwer Academic Publishers, Dordrecht.

Simon, E. \& Van Herreweghe, M., 2010, 'The relation between orthography and phonology from different angles: Insights from psycholinguistics and second language acquisition', Language and Speech 53(3), 303-306. http://dx.doi. org/10.1177/0023830910372486

Sprenger-Charolles, L., 2003, 'Linguistic processes in language and spelling: The case of Alphabetic writing systems: English, French, German and Spanish', in Handbook of Learner's Literacy, pp. 43-66, Kluwer Academic Publishers, Dordrecht, Netherlands.

Taljard, E. \& Bosch, S.E., 2006, 'A comparison of approaches to word class tagging: Disjunctively vs. Conjunctively written Bantu languages', Nordic Journal of African Studies 15(4), 428-442.

Thomson, B., Crewther, D. \& Crewther, S.G., 2006, 'Wots that Werd? Pseduowords (non-words) may be a misleading measure of phonological skills in young learne readers', Dyslexia 12(4), 289-299. http://dx.doi.org/10.1002/dys.328

Van Wyk, E.B., 1987, 'Proclitic bo of Northern Sotho', South African Journal of African Languages $7(1), 34-42$.

Widjaja, V. \& Winskel, H., 2004, Phonological awareness and word reading in a transparent orthography: Preliminary findings on Indonesian, Australian Speech Science \& Technology Association Inc., Sydney.

Wimmer, H. \& Goswami, U., 1994, 'The influence of orthographic consistency on reading development: Word recognition in English and German learners', Cognition 51, 91-103. http://dx.doi.org/10.1016/0010-0277(94)90010-8

Yamashita, J., 2013, 'Word recognition subcomponents and passage level reading in a foreign language', Reading in a Foreign Language 25(1), 52-71.

Ziegler, J.C. \& Goswami, U., 2005, 'Reading acquisition, developmental dyslexia, and skilled reading across languages: A psycholinguistic grain size theory', Psychological Bulletin 131(1), 3-29. http://dx.doi.org/10.1037/0033-2909.131.1.3 